\title{
Localizing Proton-Mediated Inhibitory Feedback at the Retinal Horizontal Cell-Cone Synapse with Genetically-Encoded pH Probes
}

\author{
DBillie Beckwith-Cohen, ${ }^{1}$ Lars C. Holzhausen, ${ }^{2}$ Tzu-Ming Wang, ${ }^{2}{ }^{\circledR}$ Rajit Rajappa, ${ }^{2}$ and ${ }^{\circledR}$ Richard H. Kramer ${ }^{1,2}$ \\ ${ }^{1}$ Vision Science Graduate Program, University of California, Berkeley, and ${ }^{2}$ Department of Molecular and Cell Biology, University of California, Berkeley, \\ California 94720-3200
}

Lateral inhibition in the vertebrate retina depends on a negative feedback synapse between horizontal cells (HCs) and rod and cone photoreceptors. A change in $\mathrm{pH}$ is thought to be the signal for negative feedback, but its spatial profile in the synaptic cleft is unknown. Here we use three different membrane proteins, each fused to the same genetically-encoded $\mathrm{pH}$-sensitive Green Fluorescent Protein (GFP) (pHluorin), to probe synaptic $\mathrm{pH}$ in retina from transgenic zebrafish (Danio rerio) of either sex. We used the cone transducin promoter to express SynaptopHluorin (pHluorin on vesicle-associated membrane protein (VAMP2)) or CalipHluorin (pHluorin on an L-type $\mathrm{Ca}^{2+}$ channel) and the HC-specific connexin-55.5 promoter to express AMPApHluorin (pHluorin on an AMPA receptor). Stimulus light led to increased fluorescence of all three probes, consistent with alkalinization of the synaptic cleft. The receptive field size, sensitivity to surround illumination, and response to activation of an alien receptor expressed exclusively in HCs, are consistent with lateral inhibition as the trigger for alkalinization. However, SynaptopHluorin and AMPApHluorin, which are displaced farther from cone synaptic ribbons than CalipHluorin, reported a smaller $\mathrm{pH}$ change. Hence, unlike feedforward glutamatergic transmission, which spills over to allow cross talk between terminals in the cone network, the $\mathrm{pH}$ change underlying HC feedback is compartmentalized to individual synaptic invaginations within a cone terminal, consistent with private line communication.

Key words: fluorescent protein; lateral inhibition; pHluorin; photoreceptor; retina; synaptic transmission

Significance Statement

Lateral inhibition (LI) is a fundamental feature of information processing in sensory systems, enhancing contrast sensitivity and enabling edge discrimination. Horizontal cells (HCs) are the first cellular substrate of LI in the vertebrate retina, but the synaptic mechanisms underlying LI are not completely understood, despite decades of study. This paper makes a significant contribution to our understanding of LI, by showing that each $\mathrm{HC}$ - cone synapse is a "private-line" that operates independently from other HC- cone connections. Using transgenic zebrafish expressing pHluorin, a pH-sensitive GFP variant spliced onto three different protein platforms expressed either in cones or HCs we show that the feedback pH signal is constrained to individual cone terminals, and more stringently, to individual synaptic contact sites within each terminal.

\section{Introduction}

Retinal horizontal cells (HCs) receive synaptic input from rod and cone photoreceptors, but they also send signals back to the

Received June 14, 2018; revised Nov. 12, 2018; accepted Nov. 17, 2018.

Author contributions: B.B.-C. wrote the first draft of the paper; B.B.-C. and R.H.K. edited the paper; B.B.-C., L.C.H., and R.H.K. designed research; B.B.-C., L.C.H., and T.-M.W. performed research; L.C.H. and T.-M.W. contributed unpublished reagents/analytic tools; B.B.-C., L.C.H., T.-M.W., and R.R. analyzed data; B.B.-C. and R.H.K. wrote the paper.

This work was supported by Grants from the U.S. National Institutes of Health to R.H.K. (R01 EY024334 and P30 EY003176) and T.-M.W. (F32 EY020095). We thank S. Brockerhoff (University of Washington) for providing SynaptopHluorin fish, M. Kamermans (Netherlands Institute for Neuroscience), R. Huganir (Johns Hopkins University School of Medicine), and A.R. McQuiston (Virginia Commonwealth University School of Medicine) for providing plasmids, Joe DeGiorgis for assisting with EM microscopy, Benjamin E. Smith for assisting with image analysis for Figure 3D, and Chris Habrian for assisting with pH Calibration for Figure $1 C$ photoreceptors to regulate release of their neurotransmitter, glutamate (Wu, 1991). HC feedback is crucial for lateral inhibition, a retinal circuit mechanism for enhancing contrast sensitivity (Campbell and Robson, 1968) and color discrimination (Tomita, 1965). Lateral inhibition at the first synapse in the retina sets the stage for antagonistic center-surround receptive fields exhibited throughout the visual system, an organizational feature that is essential for high acuity vision.

The authors declare no competing financial interests.

Correspondence should be addressed to Richard H. Kramer at rhkramer@berkeley.edu.

https://doi.org/10.1523/JNEUROSCl.1541-18.2018

Copyright $\odot 2019$ the authors $\quad 0270-6474 / 19 / 390651-12 \$ 15.00 / 0$ 
Several different chemical and electrical signals have been proposed as mediators of HC feedback (Kramer and Davenport, 2015). Identification of the feedback signal has been complicated by the reciprocal nature of the synapse and its inaccessibility because it occurs in an invagination, deep within the terminals of cones. The first proposed feedback signal was the inhibitory neurotransmitter GABA, which is synthesized and released by HCs (Schwartz, 1982). However, pharmacological blockers of GABA receptors fail to reduce HC feedback (Thoreson and Burkhardt, 1990; Verweij et al., 1996) and have no significant effect on the downstream consequences of HC-mediated lateral inhibition (Davenport et al., 2008), inconsistent with GABA serving as the HC feedback signal. Second, an electrical field effect, known as ephaptic transmission, has been proposed as an HC feedback mechanism (Byzov and Shura-Bura, 1986; Kamermans et al., 2001). The tips of HC dendrites have a high density of ion channels directly opposed to synaptic ribbons in cone terminals. Current is thought to flow through these channels and across the extracellular resistance, causing a voltage drop that is sensed by the cone voltage-gated $\mathrm{Ca}^{2+}$ channels, thereby altering $\mathrm{Ca}^{2+}$ dependent glutamate release (Verweij et al., 1996). HC to cone feedback exhibits a brief, but measurable synaptic delay, which may be inconsistent with an instantaneous ephaptic mechanism (Warren et al., 2016a), although the interpretation of these results has been debated (Cenedese et al., 2017; Chapot et al., 2017). Third, an HC-driven change in proton concentration has been proposed to serve as the HC feedback signal (Hirasawa and Kaneko, 2003; Vessey et al., 2005). In this scenario, the voltagedependent gating of L-type $\mathrm{Ca}^{2+}$ channels in cones is regulated by protonation of a site in the channel protein, again altering $\mathrm{Ca}^{2+}$-dependent glutamate release.

Most of the evidence, pro or con, about each of the three proposed signals has involved genetic or pharmacological manipulations intended to block or mimic signal transduction. By contrast, demonstrating whether a putative signal is actually present at the synapse, at a level sufficient to account for feedback inhibition, has been more challenging. The one exception is $\mathrm{pH}$. The development of pHluorin, a genetically-encoded protein probe for $\mathrm{pH}$, circumvents the inaccessibility problem by allowing local optical measurement of $\mathrm{pH}$, providing a direct test of the pH hypothesis. In a previous study (Wang et al., 2014), we developed the novel fluorescent probe CalipHluorin, in which pHluorin was spliced onto the extracellular side of the accessory $\alpha_{2} \delta_{4}$ subunit of the L-type $\mathrm{Ca}^{2+}$ channel. CalipHluorin was particularly well situated as a probe because L-type channels are the relevant targets for HC feedback in cones (Verweij et al., 1996; Cadetti and Thoreson, 2006). Here, to learn about the spatial profile of the proton signal and determine whether it spills over to adjacent synapses, we use two additional protein platforms for pHluorin and exploit the advantages of zebrafish genetics to display these probes in a cell-type-specific manner.

\section{Materials and Methods}

Transgenic fish. Transgenic fish expressing CalipHluorin (ZFIN ID: ZDB-FISH-150901-12656) and/or FaNaC (ZFIN ID: ZDB-FISH150901-9090) were engineered previously (Wang et al., 2014). SynaptopHluorin fish (ZFIN ID: ZDB-FISH-150901-24914; Holzhausen et al., 2009) were kindly donated by S. Brockerhoff, University of Washington. AMPApHluorin fish (ZFIN ID: ZDB-FISH-181031-4) were generated specifically for this project. The rat GluR2 subunit of the AMPA receptor was generously provided by R. Huganir, Johns Hopkins University School of Medicine. A tandem sequence containing the superecliptic pHluorin, a protease recognition site and a 15 residue linker was inserted between the predicted signal peptide and the coding sequence of the
GluR2 subunit. The resulting construct was cloned into vector pDONR221 (Invitrogen) to produce pME-AMPApHluorin. Gateway recombination cloning (Invitrogen) with p5E-Cx55.5 (Shields et al., 2007; kindly provided by M. Kamermans, Netherlands Institute for Neuroscience), pME-AMPApHluorin, and p3E-MTpA and pDestTol2CG2 from the Tol2kit (Kwan et al., 2007) were used for generating the AMPApHluorin construct. One- or two-cell-stage zebrafish (Danio rerio, $\mathrm{AB}$ strain) embryos were microinjected with the construct together with Tol2 mRNA for a higher germline transmission rate (Kwan et al., 2007). The transgene-positive F0 founders were selected by screening for green heart fluorescence in embryos at 2-4 d postfertilization (Kwan et al., 2007 ) and raised at $28.5^{\circ} \mathrm{C}$ in a $14 \mathrm{~h} \mathrm{light} / 10 \mathrm{~h}$ dark cycle. The adult F0 fish were inbred, and their transgene-positive progeny were screened by green heart fluorescence, raised, and used for imaging experiments and immunohistochemistry.

To generate SynaptopHluorin and $\mathrm{FaNaC}$ double-transgenic fish, the SynaptopHluorin transgenic fish line was crossed with the $\mathrm{FaNaC}$ fish line. Embryos and larvae were treated with phenylthiourea (PTU) to prevent pigmentation and phenotypically screen for both transgenes at dpf4. For SynaptopHluorin the expression of pHluorin (GFP) was identified in the cone layer in larval eyes (thus necessitating the use of PTU). $\mathrm{FaNaC}$ was identified by positive green heart fluorescence.

Tissue preparation. Adult zebrafish (Danio rerio) of either sex were used in all experiments. Procedures, animal care, and use were approved by the University of California, Berkeley Animal Care and Use Committee. Fish were dark adapted for $>30 \mathrm{~min}$, and sacrificed by immersion in $400 \mathrm{mg} / \mathrm{L}$ MS-222 followed by decapitation. Retinas were removed from retinal pigment epithelium under infrared light. For immunohistochemistry eyes were fixed in $4 \%$ paraformaldehyde, rinsed in PBS, and immersed for $1 \mathrm{~h}$ in $15 \%$ sucrose followed by $1 \mathrm{~h}$ in $30 \%$ sucrose for cryoprotection. The eyes were embedded in tissue-freezing medium (General Data), flash-frozen over dry ice, and kept in $-80^{\circ} \mathrm{C}$ until use. Eyes were sliced to $14 \mu \mathrm{m}$ in thickness using a microtome (ThermoFisher, Microm HM550) and kept at $-20^{\circ} \mathrm{C}$ until immunohistochemistry was performed.

Solutions. Unless specified otherwise, retinas were continuously perfused with bicarbonate-buffered saline solution containing the following (in mM): $100 \mathrm{NaCl}, 2.5 \mathrm{KCl}, 1 \mathrm{MgCl}_{2}, 1 \mathrm{CaCl}_{2}, 0.4$ ascorbic acid, 20 dextrose, and $25 \mathrm{NaHCO}_{3}$ bubbled with $5 \% \mathrm{CO}_{2}$ and $95 \% \mathrm{O}_{2}$, pH 7.3. For the $\mathrm{pH}$ experiments on rat hippocampal cells, the solution contained the following (in mM): $115 \mathrm{NaCl}, 2.5 \mathrm{KCl}, 1 \mathrm{MgCl}_{2}, 1 \mathrm{CaCl}_{2}$, and 20 dextrose as well as with $20 \mathrm{~mm}$ of one of the following buffers: $2-(\mathrm{N}$ morpholino) ethanesulfonic acid (MES) for $\mathrm{pH} 5.5$ and HEPES for $\mathrm{pH}$ 7.4. Light-response experiment buffers contained the same solution as that used in $\mathrm{pH}$ experiments with the addition of $0.4 \mathrm{~mm}$ ascorbic acid and 20 mM HEPES. pH titration solutions (Fig. 1C) contained the following (in mM): MES buffer: $150 \mathrm{NaCl}, 4 \mathrm{KCl}, 2 \mathrm{CaCl}_{2}, 1 \mathrm{MgCl}_{2}, 10$ glucose, and $10 \mathrm{MES}$; HEPES buffer: $150 \mathrm{NaCl}, 4 \mathrm{KCl}, 2 \mathrm{CaCl}_{2}, 1 \mathrm{MgCl}_{2}$, 10 glucose, and 10 HEPES.

Immunohistochemistry and antibodies. Protein blocking solution used for immunohistochemistry included $34.5 \mathrm{ml}$ of PBS, $0.5 \mathrm{ml}$ Triton X-100 (Sigma-Aldrich) diluted to $10 \times$ in PBS and $15 \mathrm{ml}$ bovine serum albumin fraction V ( $1 \mathrm{~g} / 100 \mathrm{ml}$; MP Biomedicals, catalog \#160069), chilled to $4^{\circ} \mathrm{C}$. Additional blocking was achieved using unconjugated secondary antibodies. Tissue sections were rinsed on a shaker in chilled PBS for three 5 min cycles at $100 \mathrm{rpm}$, with fresh PBS used for each cycle. Sections were immersed in chilled blocking solution including goat anti-mouse (ThermoFisher Scientific, catalog \#A16080; RRID:AB_2534754) and donkey anti-rabbit unconjugated igG (ThermoFisher Scientific, catalog \#31238; RRID:AB_429690) antibodies at a 1:1000 dilution and placed on a shaker for $1 \mathrm{~h}$ at $100 \mathrm{rpm}$. The sections were rinsed on a shaker in chilled PBS for three 5 min cycles at $100 \mathrm{rpm}$. The sections were immersed by placing 200 $\mu \mathrm{l}$ fresh blocking solution including mouse anti-GFP monoclonal unconjugated antibody (Abcam, catalog \#ab1218; RRID:AB_298911) and rabbit IgG anti-CtBp2 (RIBEYE labeling, ThermoFisher Scientific, catalog \#PA5-30001; RRID:AB_2547475) polyclonal unconjugated antibody, both at a 1:400 dilution. Sections were covered using a gasket and placed on a shaker at $100 \mathrm{rpm}$ in a $4^{\circ} \mathrm{C}$ cold room for $36-48 \mathrm{~h}$. Negative controls included sections of the same tissue while omitting the primary 

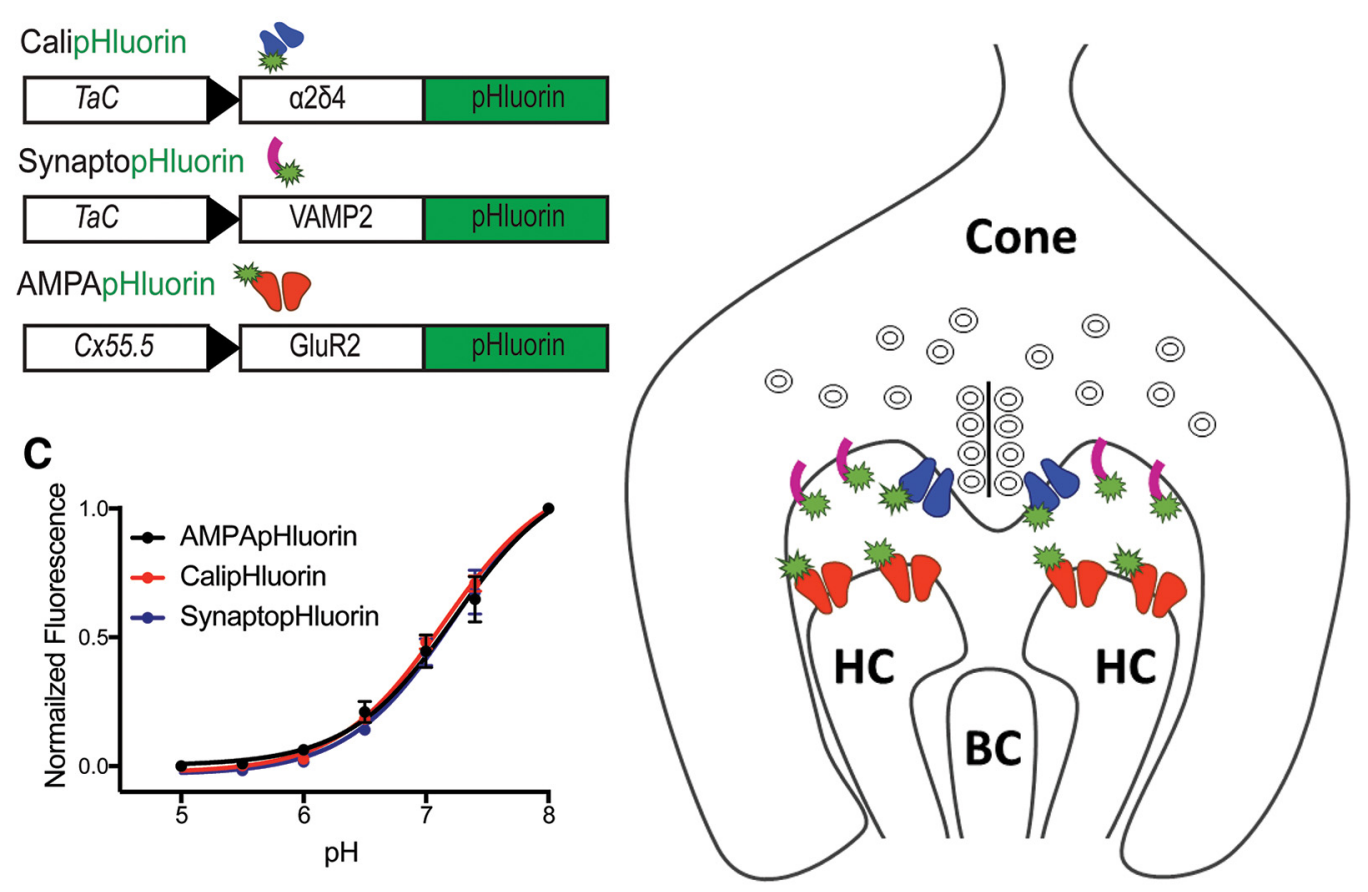

Figure 1. Three genetically encoded pH probes for studying the HC- cone synapse. $A$, Three pHluorin constructs. CalipHluorin, driven by the TaC promoter, is pHluorin fused onto the $\alpha 2 \delta 4$ subunit of the L-type $\mathrm{Ca}^{2+}$ channel. SynaptopHluorin, also driven by TaC, is pHluorin fused onto the SNARE protein VAMP2. AMPApHluorin is pHluorin fused onto the $\alpha 2$-subunit of an ionotropic glutamate receptor. B, Proposed architecture of pHluorin within the invaginating synapse. CalipHluorin and SynaptopHluorin are on cone terminals; AMPApHluorin is on HC dendrites. A bipolar cell (BC) dendrite forms the third element of the synaptic triad. C, The estimated pKa of pHluorin is not altered when tagged to different cellular proteins. The average normalized change in fluorescence from three experiments is plotted as a function of $\mathrm{pH}$. The number of cells used in the averaged data were as follows: SynaptopHluorin $(n=18)$, AMPApHluorin $(n=13)$, CalipHluorin $(n=10)$. The respective colored solid lines are fits to the simple Henderson-Hasselbach equation data is expressed as mean SEM.

antibodies. The sections were rinsed on a shaker in chilled PBS for three 5 min cycles at $100 \mathrm{rpm}$ and immersed in blocking solution including AlexaFluor 488 goat anti-mouse igG (ThermoFisher Scientific, catalog \#A-11001; RRID:AB_2534069) and AlexaFluor 647 donkey anti-rabbit IgG (ThermoFisher Scientific, catalog \#A-31573; RRID:AB_2536183) antibodies at 1:1000 dilution. The sections were placed on a shaker for $1 \mathrm{~h}$, the rinsed for three cycles, air dried, and sealed using Fluoromount-G with DAPI mounting solution (Invitrogen).

HEK293T cell pHluorin titration. HEK293T cells grown on $18 \mathrm{~mm}$ coverslips coated with poly-lysine (Sigma-Aldrich) were transfected $1 \mathrm{~d}$ after plating with $2 \mu \mathrm{g} /$ well CalipHluorin or AMPApHluorin plasmids. A day after transfection, pHluorin imaging was performed on a confocal Carl Zeiss LSM780 microscope while perfusing with solutions of a $\mathrm{pH}$ ranging from 5.0 to 8.0. MES-based buffer was used to prepare solutions for $\mathrm{pH}$ 5-6.5 and HEPES based buffer was used to prepare solutions with $\mathrm{pH} 7-8$.

Image acquisition. Flat-mounted retinae were transferred to an imaging chamber with the photoreceptor side facing the bottom of the chamber. We used a custom-built two-photon microscope as described previously (Wang et al., 2014). The microscope was controlled by ScanImage r3.6 software (Pologruto et al., 2003) with in-house developed plugins. For light stimulation experiments, an area $30 \times 30 \mu \mathrm{m}^{2}$ was imaged at a frame rate of $128 \mathrm{~ms}$ per frame and binned into $64 \times 64$ pixel images. Immunohistochemistry- for super resolution experiments we used a confocal Carl Zeiss LSM880 microscope equipped with Airyscan set to super resolution mode. AlexaFluor 488 and 647 were excited at 488 $\mathrm{nm}$ and $633 \mathrm{~nm}$ using Argon and HeNe lasers respectively; DAPI was excited using a diode $405 \mathrm{~nm}$ laser.

Light stimulation. Light stimulation was performed as previously described (Wang et al., 2014). Briefly, light sources were a LUXEON Rebel Blue light-emitting diode (LED; Philips) short-pass filtered at $460 \mathrm{~nm}$ and a LUXEON Rebel Amber LED long-pass filtered at $550 \mathrm{~nm}$. Light from the two LEDs was combined with a $505 \mathrm{~nm}$ long-pass dichroic mirror and coupled to the projection optics with an optical fiber. The green portion of the spectrum $(460-550 \mathrm{~nm})$ was filtered out to protect the photomultiplier from photodamage. We used a light intensity of $10^{18}-10^{19}$ photons $\mathrm{m}^{-2} \cdot \mathrm{s}^{-1}$ (Davenport et al., 2008) measured with a photometer at the specimen plane. A pattern mask (e.g., spot or annulus) was placed in the projection light and projected onto retinae through the condenser. A program written in MATLAB (MathWorks) was used to command the shutter (TS6B, UNIBLITZ) for controlling flash duration. A flash duration of $508 \mathrm{~ms}$ was used. Light stimulation was given at $\sim 1 \mathrm{~s}$ after the beginning of a scan series and was repeated three times in each experimental run.

Image analysis. A region-of-interest (ROI) was selected from the cone-HC terminal image. The ROI was generated in ImageJ (https:// rsbweb.nih.gov/ij) using a thresholding-based technique as previously described (Wang et al., 2014). We excluded from the ROI the first row of pixels (i.e., the first $2 \mathrm{~ms}$ of the scanned image), collected after terminating the light flash, to avoid detecting afterglow of the stimulation light. The background signal, measured at the end of the experiment in the absence of laser scanning, was subtracted from each image. To estimate photobleaching, the average pixel intensity within the ROI of each frame (termed $F$ ) was fitted with a single-exponential function $y=a e^{-b x}$, where $x$ is the frame number and $y$ is the intensity as previously described (Wang et al., 2014). Fluorescence intensities acquired during the light flash were excluded from the photobleach fitting routine because they were confounded with the stimulus light as previously described (Wang et al., 2014). To compensate for photobleaching, the original intensity $(F)$ of each frame was divided by its corresponding value in the fitted curve $(y)$. The compensated light responses from the three flashes were aligned, and the mean response was calculated and defined as $n$ of 1 as previously described (Wang et al., 2014). For Figure $3 D$ a radial intensity profile was created for each probe using ROIs generated in ImageJ around individual terminals. Image resolutions were matched and sumprojection intensity profiles were generated using a macro written for 
this purpose. Variations in terminal intensity were normalized and each sample was analyzed independently so that dim images carry the same weight as bright ones in the final analysis.

For Figure $1 C$, quantitative analysis was performed using ImageJ. Data were generated from two different regions in each experiment. The average normalized change in fluorescence from those regions was plotted as a function of $\mathrm{pH}$. The magnitude of normalized fluorescence change as a function of $\mathrm{pH}$ was fitted to a simple Henderson-Hasselbach equation, $y=y_{0}+y_{\max } /[1+10(\mathrm{pKa}-\mathrm{pH})]$, where $y_{0}$ represents the offset, $y_{\max }$ the dynamic range, and $\mathrm{pKa}$ is the logarithm of equilibrium constant for protonation.

Electron microscopy. Zebrafish retinae were fixed and prepared for electron microscopy using standard methods as previously described (Rea et al., 2004). Images were obtained using Advanced Microscopy Techniques digital camera imaging systems for transmission electron microscopes (Scientex).

Experimental design and statistical analysis. Unless otherwise noted, sample sizes for each experimental condition represent independent frames imaged from at least four zebrafish retinas with the mean fluorescence of many individual terminals averaged to give a single value for each frame. Statistical significance for sample numbers $<10$ was determined by using the two-sided nonparametric Mann-Whitney $U$ test. Significance for multiple group comparisons was determined using oneway ANOVA followed by the two-tailed Student's $t$ test. Significance was otherwise determined by two-tailed Student's $t$ test. Data points and error bars represent the mean \pm SEM. Statistics were performed using Microsoft Office Professional Excel v2016, IGOR Pro 8, or MATLAB 9.

\section{Results \\ CalipHluorin, SynaptopHluorin, and AMPApHluorin: three genetically-encoded $\mathrm{pH}$ reporters for investigating proton signaling at the $\mathrm{HC}$-cone synapse}

We exploited the unique subcellular distributions of key signaling proteins to explore the light-elicited proton gradient in the HC-cone synapse (Fig. 1). CalipHluorin, described previously (Wang et al., 2014), was designed to detect local pH directly at the cone $\mathrm{Ca}^{2+}$ channels that mediate neurotransmitter release. Cone-specific expression of CalipHluorin is driven with the promoter for the cone transducin $\alpha$-subunit (TaC; Kennedy et al., 2007). Electron microscopy (Raviola and Gilula, 1975) and immunofluorescence microscopy (Mercer et al., 2011) suggest that the $\mathrm{Ca}^{2+}$ channels are positioned directly adjacent to synaptic ribbons in cones, which would place CalipHluorin very close to the sites of neurotransmitter release, and exactly on the relevant physiological target protein regulated by HC feedback.

SynaptopHluorin (Miesenböck et al., 1998) is pHluorin fused onto the C-terminus (luminal or extracellular side) of VAMP2 (also called synaptobrevin), a synaptic vesicle protein that is part of the SNARE complex. Cone-specific expression of VAMP2 was also driven by the TaC promoter (Holzhausen et al., 2009). SynaptopHluorin has been used as a probe of exocytosis, because it becomes fluorescent only when acidic synaptic vesicles fuse with the plasma membrane, exposing the probe to the neutral $\mathrm{pH}$ of the extracellular space (Miesenböck et al., 1998; Sankaranarayanan and Ryan, 2000). However, a large fraction of VAMP2 molecules escape endocytotic recapture and remain stranded on the plasma membrane where they are sensitive to extracellular $\mathrm{pH}$ (Sankaranarayanan and Ryan, 2000).

Finally, AMPApHluorin is pHluorin fused onto the $\alpha 2$ subunit of an ionotropic glutamate receptor (previously called pHluorin-GluR2; Ashby et al., 2004). The connexin-55.5 promoter ensures that AMPApHluorin is expressed selectively in HCs (Shields et al., 2007).

Because the identical pHluorin variant was used in all three probes, the dependence of fluorescence on $\mathrm{pH}$ should also be identical. We verified this by perfusing various $\mathrm{pH}$-buffered solutions on HEK293 cells expressing either CalipHluorin or AMPApHluorin and on retinae expressing SynaptopHluorin. The titration curves were identical, with a pKa of $7.15 \pm 0.04$ for CalipHluorin, 7.22 \pm 0.08 for SynaptopHluorin, and 7.23 \pm 0.10 for AMPApHluorin (Fig. 1).

\section{Distinct distributions of the $\mathrm{pH}$ reporters at the synapse}

We generated transgenic zebrafish lines that stably express these three probes, each containing the same superecliptic pHluorin variant of GFP. In the retina, the fluorescence intensity of each probe depends on two factors: the expression density of the probe and the local $\mathrm{pH}$ to which it is exposed. To disambiguate these factors, we first compared the expression density of each probe by immunostaining the retina with a fluorescent antibody against GFP. We used super-resolution microscopy (Zeiss, Airyscan) on thin retinal slices (Fig. 2) to provide images with 140-250 nm resolution, much better than possible with direct two-photon imaging of fluorescent probes such as pHluorin $>500 \mathrm{~nm}$ (Svoboda and Yasuda, 2006). To visualize synaptic ribbons, we used a fluorescent antibody to label RIBEYE, its main structural protein (Schmitz et al., 2000).

We found that in cone terminals, CalipHluorin was juxtaposed to the synaptic ribbons, matching the normal location of the voltage-gated $\mathrm{Ca}^{2+}$ channels in cones. SynaptopHluorin was more dispersed throughout the cone terminals, consistent with diffusion of VAMP2 from synaptic release sites by lateral diffusion in the plasma membrane of the terminal (Sankaranarayanan and Ryan, 2000). AMPApHluorin was present throughout the HCs, both in the cell bodies and dendrites. Some of the AMPApHluorin protein appeared in puncta, perhaps corresponding to intracellular compartments, a common consequence of overexpression.

Next, we examined the resting pHluorin fluorescence of each of the probes in darkness; i.e., without visible wavelengths of light. Retinas were continuously imaged with two-photon microscopy using $910 \mathrm{~nm}$ light. Although infrared two-photon scanning can generate a rod light response and some degree of light adaptation (Denk and Detwiler, 1999), both should reach steady-state with continuous imaging, allowing measurement of signals elicited by a bright flash of visible light. Figure $3 \mathrm{~A}$ shows that steady-state SynaptopHluorin and CalipHluorin fluorescence was detected throughout cones, including in outer segments and inner segments, but the signal was brightest in cone terminals. AMPApHluorin fluorescence was distributed throughout HCs, but brightest in rosettes near the periphery of the cone terminals (Fig. 3B). AMPApHluorin fluorescence also appeared in isolated smaller puncta, at the tips of $\mathrm{HC}$ dendrites adjacent to rod terminals (Fig. 3B). Similar rosettes and isolated smaller puncta have been observed in zebrafish retina stained with an antibody against the GluR2 protein (Klooster et al., 2009). Hence in the synaptic region, the distribution of steady-state $\mathrm{pHluorin}$ probe fluorescence coincides with the antibody labeling.

We analyzed the distribution of the fluorescence signal at HCcone contacts by imaging hundreds of individual terminals in retinal flat mounts from zebrafish with CalipHluorin $(n=486)$, SynaptopHluorin $(n=167)$ or AMPApHluorin $(n=320)$. For each probe, an average spatial profile and associated heat map were generated (Fig. 3C,D). The average peak intensity was 540 $\mathrm{nm}$ from the terminal center for CalipHluorin, $995 \mathrm{~nm}$ for AMPApHluorin, and $1200 \mathrm{~nm}$ for SynaptopHluorin. Consistent with the immunolabeling results, we found that the intrinsic fluorescence signals from SynaptopHluorin and AMPApHluorin 

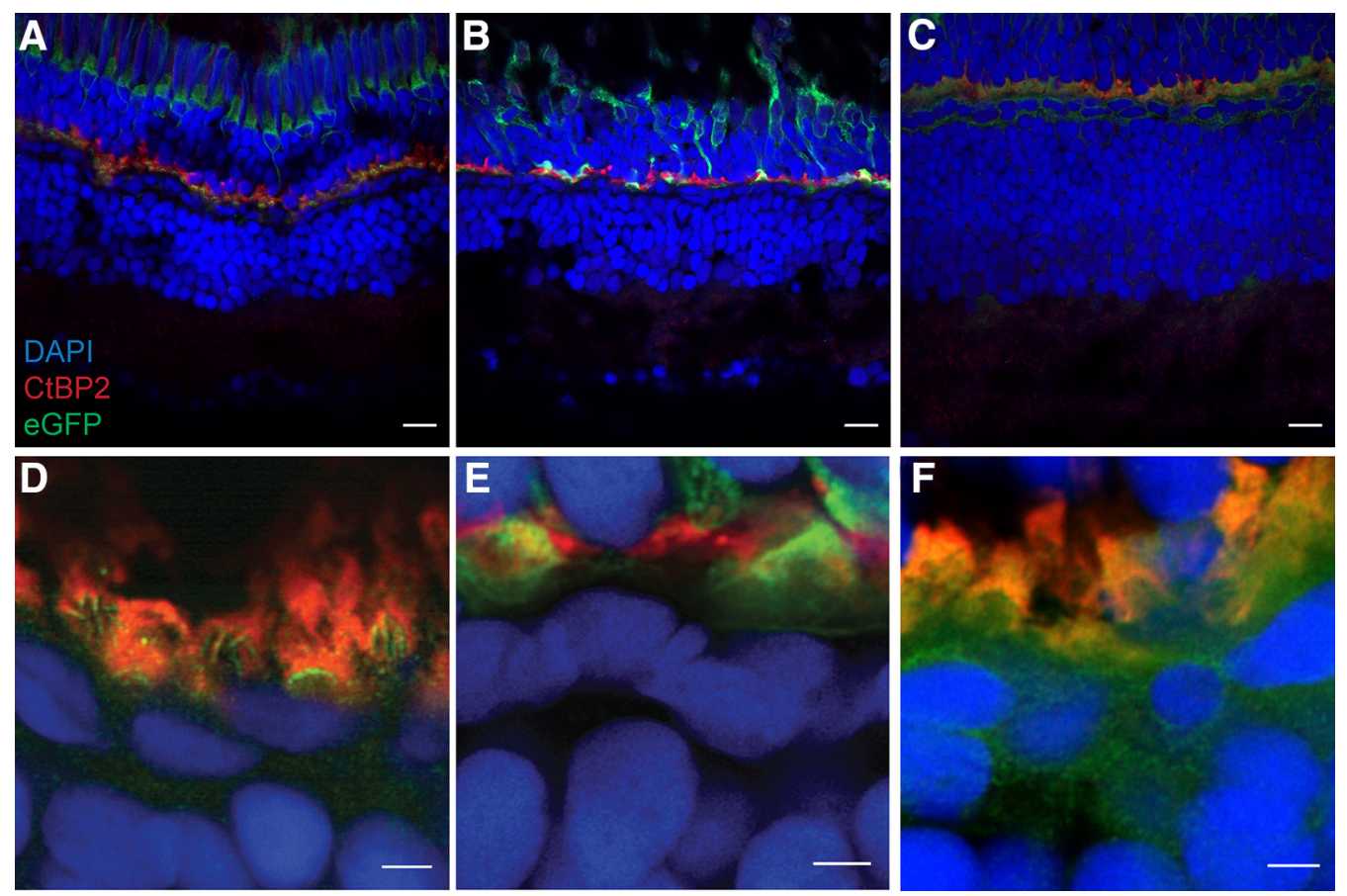

Figure 2. Immunolocalization of CalipHluorin, SynaptopHluorin and AMPApHluorin in the retina. Antibody against GFP labels pHluorin (green), antibody against CtBP2 labels RIBEYE (red), and DAPI labels cell nuclei (blue). $\boldsymbol{A}$, CalipHluorin labeling is restricted to cones, including in inner segments, outer segments, and terminals. $\boldsymbol{B}$, SynaptopHluorin is also limited to cones, appearing in inner segments, outer segments, and terminals. C, AMPApHluorin is limited to HCs. D, Within the terminals, CalipHluorin is juxtaposed to synaptic ribbons, which contain RIBEYE. $\boldsymbol{E}$, Within the terminals, labeling of SynaptopHluorin is diffuse. $\boldsymbol{F}$, AMPApHluorin appears diffusely throughout horizontal cell soma and dendrites. Scale bars: $A-C, 10 \mu \mathrm{m} ; \mathbf{D}-\boldsymbol{F}, 2 \mu \mathrm{m}$.

were maximal at the perimeter of the terminal, while CalipHluorin fluorescence was maximal closer to the center of the terminal.

\section{SynaptopHluorin reports synaptic cleft $\mathrm{pH}$ changes resulting from HC feedback}

Once we established the fluorescence of the pHluorin probes in darkness, we investigated how light stimuli lead to a change in fluorescence. Our previous studies showed that light stimuli lead to a $5 \%$ increase in CalipHluorin fluorescence, indicating alkalinization of $\sim 0.2 \mathrm{pH}$ units in the synaptic cleft (Wang et al., 2014). Because we could not image during the light flash, we had to measure the remaining "tail" of the fluorescence change immediately after the $508 \mathrm{~ms}$ light flash. Therefore the brief acidification of extracellular $\mathrm{pH}$ caused by cone synaptic vesicle exocytosis ( $\sim 10 \mathrm{~ms}$; DeVries, 2001) was undetectable, as reported previously for CalipHluorin (Wang et al., 2014). We asked whether SynaptopHluorin, also on cone terminals, similarly registers HC-dependent alkalinization with light stimuli (Fig. 4). To stimulate a cone light response and trigger consequent $\mathrm{HC}$ feedback, we applied a single $500 \mathrm{~ms}$ flash of full-field light while imaging with repeated two-photon scans at $125 \mathrm{~ms}$ intervals. By comparing SynaptopHluorin fluorescence immediately after the flash $(F)$ to that measured before the flash $\left(F_{0}\right)$, we observed that the stimulus caused a $2 \%$ increase in fluorescence $\left(F / F_{0}=\right.$ $1.019 \pm 0.005 ; n=15, p=1 \times 10^{-6}$; Fig. $\left.4 A, D\right)$, smaller $(p=$ $2.2 \times 10^{-5}$ ) than the previously measured change in CalipHluorin ( $~ 5 \%$; Wang et al., 2014), but still indicating significant alkalinization. SynaptopHluorin has been used extensively as a probe for exocytosis (Sankaranarayanan and Ryan, 2000), but light decreases cone exocytosis (Rea et al., 2004). Thus, the fluorescence increase triggered by the light flash in these experiments is inconsistent with an exocytotic-induced decrease in the density of probes on the cell surface. Instead, we propose that the fluores- cence increase is caused by alkalinization of the synaptic cleft, as we showed previously with CalipHluorin (Wang et al., 2014).

Fluorescence was brightest immediately after the flash and returned to baseline within $500 \mathrm{~ms}$, similar to the time course of the change in CalipHluorin fluorescence after a flash (Wang et al., 2014). Like CalipHluorin, the change in SynaptopHluorin fluorescence was eliminated by substituting the weak $\mathrm{pH}$ buffer bicarbonate $(25 \mathrm{mM})$ with the stronger and faster $\mathrm{pH}$ buffer HEPES $\left(20 \mathrm{~mm} ; F / F_{0}=1.003 \pm 0.006 ; n=6, p=0.93 ;\right.$ Fig. $\left.4 B\right)$. Also like CalipHluorin, the change in SynaptopHluorin fluorescence was eliminated with the AMPA receptor antagonist GYKI (50 $\mu$ m; $F / F_{0}=1.003 \pm 0.003, n=23, p=0.31$; Fig. $\left.4 A, D\right)$, suggesting that the source of the alkalinization was not cones, which have no native AMPA receptors (Haverkamp et al., 2001), but rather HCs, which have native AMPA receptors.

To further determine the source of the alkalinization detected by SynaptopHluorin, we stimulated the retina with spots of light while imaging fluorescence in cones located within the center of the spot. If a signal from HCs generates the alkalinization, then a small spot should generate a weaker response than a large spot, as the $\mathrm{HC}$ response is caused by a convergence of inputs from many photoreceptors onto the wide dendritic projections of a HC. An annulus of light (300 $\mu \mathrm{m}$ inner diameter, $1000 \mu \mathrm{m}$ outer diameter) elicited a similar change in fluorescence as a full field light stimulus $\left(F / F_{0}=1.017 \pm 0.003, n=15, p=0.0002\right)$, and was blocked by GYKI (1.005 $\pm 0.003, n=8, p=0.086$; Fig. $4 C, D)$, indicating that alkalinization can be detected even though cones in the $50 \mu \mathrm{m}$ central area were not directly exposed to light. Consistent with summation over a large collecting area, we found that a small spot ( $50 \mu \mathrm{M}$ diameter) that covers only the imaged area (50 $\mu \mathrm{M}$ diameter) elicited no significant SynaptopHluorin response $\left(F / F_{o}=1.006 \pm 0.003, n=15, p=0.058\right.$; Fig. $\left.4 A, D\right)$, whereas larger spots elicited significant responses that grew in- 
A

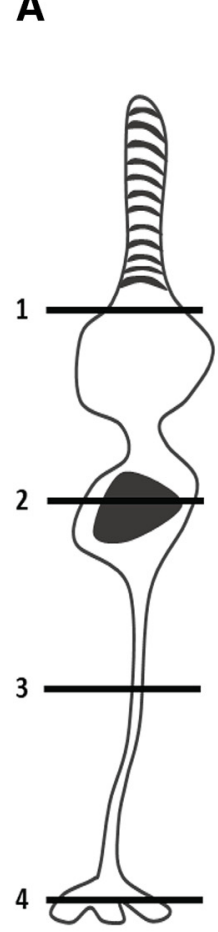

B
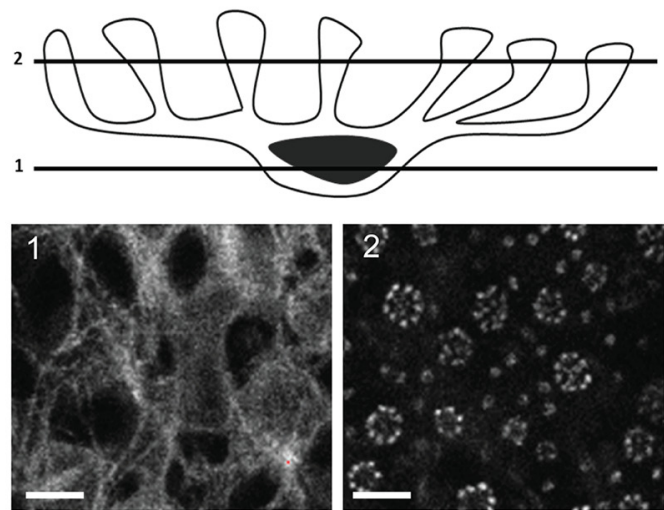
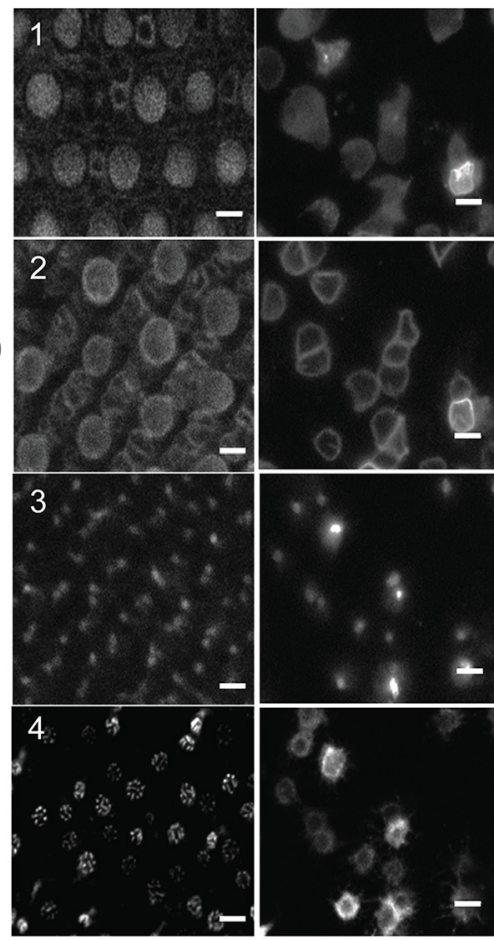

C

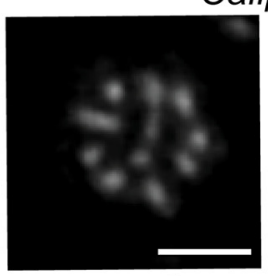

CalipHluorin

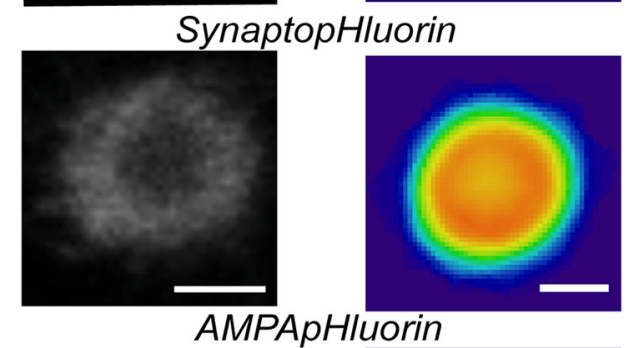

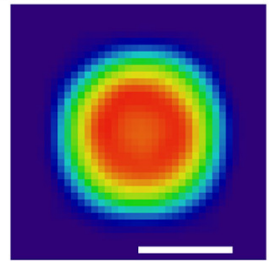

Hluorin

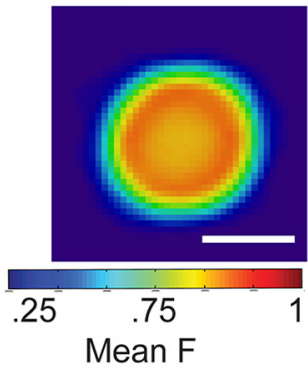

.25

D
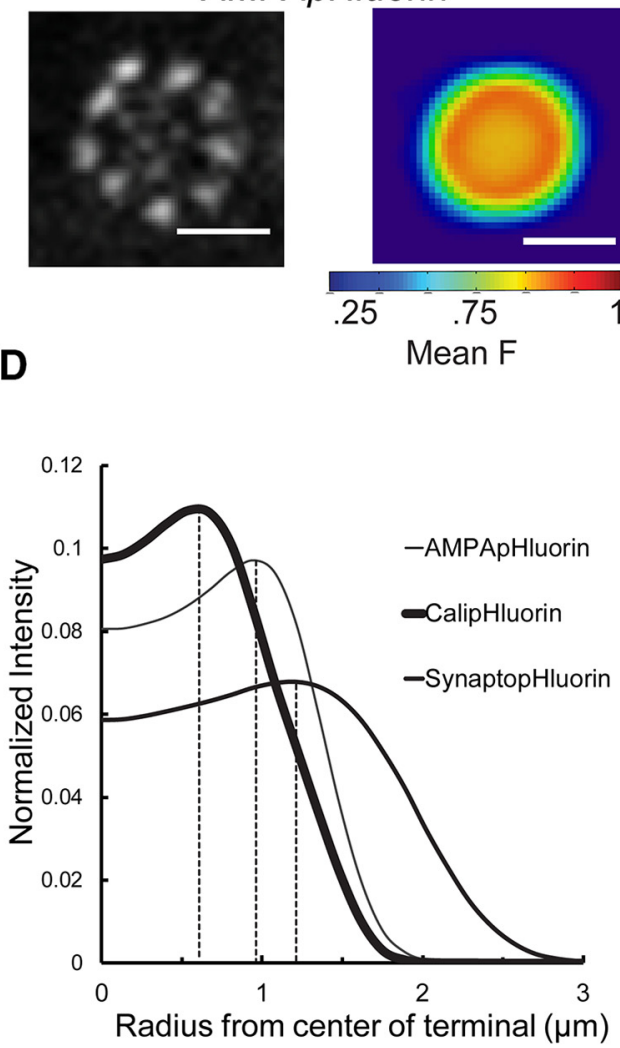

Figure 3. Spatial profiles of CalipHluorin, SynaptopHluorin, and AMPApHluorin fluorescence in darkness. $\boldsymbol{A}$, Left, Diagram of a cone with optical planes of section (numbered 1-4). CalipHluorin (middle) and SynaptopHluorin fluorescence (right) at the four imaging planes. Scale bar, $5 \mu \mathrm{M}$. B , Diagram of a HC with optical planes of section for imaging (numbered 1-2). AMPApHluorin fluorescence is detected throughout HCs, but especially intense in rosettes at cone terminals and individual puncta at rod terminals. Scale bar, $5 \mu$ m. $C$, Representative image (left) and heat maps of fluorescence intensity, averaged over hundreds of terminals (right) from CalipHluorin-, SynaptopHluorin-, and AMPApHluorin-expressing retinas. Scale bar, $2 \mu$ m. $D$, Distribution of fluorescence as a function of distance from the center of each probe.

creasingly strong up to a diameter of $500 \mu \mathrm{m}(p<0.001$; Fig. $4 D)$, typical of the dendritic tree diameter of HCs in zebrafish retina (Daniels and Baldridge, 2011). Hence the receptive field characteristics of the SynaptopHluorin response are consistent with signaling by laterally projecting HCs.

To verify that HCs are the source of the $\mathrm{pH}$ change detected by SynaptopHluorin, we bypassed the photoreceptors entirely and directly manipulated the membrane potential of HCs. We used a depolarizing ligand-gated ion channel and a complementary ligand, both of which originated from invertebrate nervous systems and are foreign to zebrafish. SynaptopHluo- rin fish were crossed with transgenic fish expressing the alien channel, named FaNaC [FMRFamide (PheMetArgPhe-NH2)gated $\mathrm{Na}^{+}$channel; Lingueglia et al., 1995]. HC-specific expression was driven with the promoter for connexin 55.5. The SynaptopHluorin-FaNaC fish showed a decrease in fluorescence in response to $30 \mu \mathrm{M}$ FMRFamide, consistent with depolarization of HCs, causing acidification of the synaptic cleft $\left(F / F_{0}=0.828 \pm 0.02, n=7, p=0.0005\right)$. SynaptopHluorin fish that did not express $\mathrm{FaNaC}$ showed no change in fluorescence $\left(F / F_{0}=0.999 \pm 0.005, n=5, p=0.99\right.$; Fig. 5$)$. The FMRFamide-induced acidification occurred even when cone 
A



C

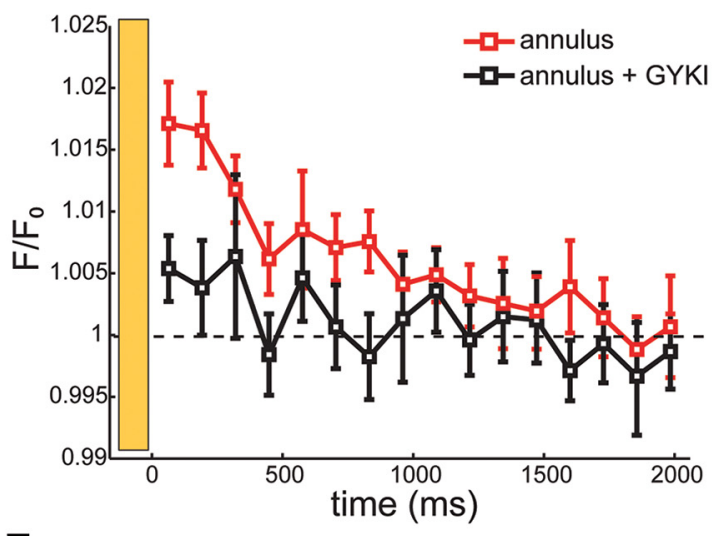

E



B



D

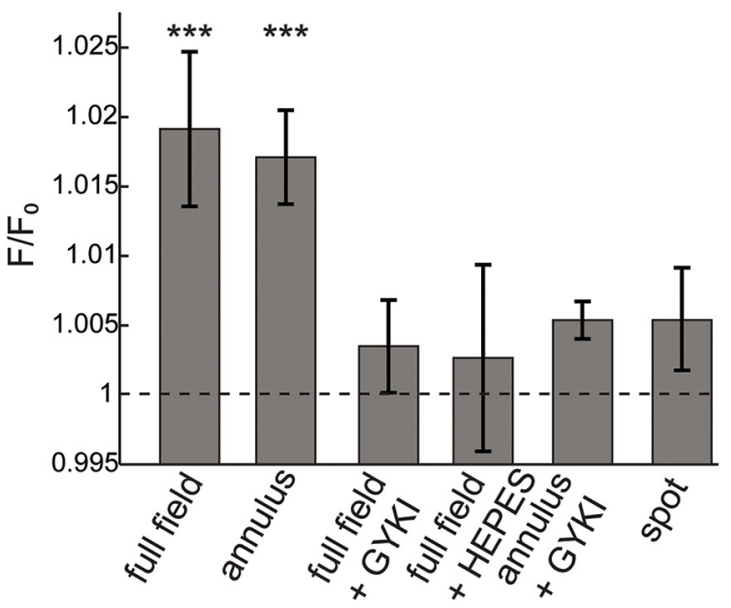

Figure 4. SynaptopHluorin reports HC-mediated changes in $\mathrm{pH}$ after a light flash. Images of SynaptopHluorin expression cone terminals were collected before a light flash and for $\sim 2 \mathrm{~s}$ after the light flash. $\boldsymbol{A}$, Fluorescence intensity was brightest immediately after the light flash (yellow bar). Full-field illumination for $0.5 \mathrm{~s}$ caused a $1.9 \%$ increase in average pixel intensity at the terminals. This response was not present when using a $50 \mu \mathrm{m}$ spot stimulus. $\boldsymbol{A}-\boldsymbol{C}$, Both $\mathrm{HC}$ feedback inhibitors, GYKI and HEPES, abolish the light-elicited pH response. $\boldsymbol{C}$, Similarly to $\mathrm{CalipHluorin}$, the $\mathrm{pH}$ response can be driven by surround illumination with an annulus (inner diameter, $300 \mu \mathrm{m}$; outer diameter, $1000 \mu \mathrm{m}$, excluding the imaged area). $\boldsymbol{D}$, Group data of the initial change in SynaptopHluorin fluorescence at the first time point ( $125 \mathrm{~ms}$ ) after the light flash and under different experimental conditions. Statistical comparisons are with respect to $F / F_{0}=1.0 . E$, SynaptopHluorin fluorescence increases with spot diameter reaching a maximum at $500 \mu \mathrm{m}$. Unless otherwise noted, sample sizes for each experimental condition represent independent frames imaged from at least four zebrafish retinas with the mean fluorescence of many individual terminals averaged to give a single value for each frame. In this and other figures, variability among data is expressed as mean \pm SEM. ${ }^{* * *} p<0.001$.

$\mathrm{Ca}^{2+}$ channels were blocked with nifedipine and HC AMPA receptors were blocked with GYKI $\left(F / F_{0}=0.841 \pm 0.04, n=\right.$ $6, p=0.038$ compared with controls, $p=0.90$ compared with FMRFamide only; Fig. 5). This result indicates that FMRFamide-elicited change in $\mathrm{pH}$ is mediated by HCs, and is not dependent on cones.

\section{AMPApHluorin expressed in $\mathrm{HC}$ dendrites also reports $\mathrm{pH}$} changes in the synaptic cleft

Next, we turned to AMPApHluorin. Before moving to transgenic expression in zebrafish retina, we verified that AMPApHluorin is sensitive to $\mathrm{pH}$ by transfecting CMV-AMPApHluorin into cultured hippocampal neurons from rat and superfusing solutions 




$$
\begin{aligned}
& -\mathrm{No} F \mathrm{FaNaC} \\
& \square \mathrm{FaNaC} \\
& \square \mathrm{FaNaC}+\mathrm{GYKI}+\mathrm{Nif}
\end{aligned}
$$

Figure 5. SynaptopHluorin reports changes in pH after agonist-induced depolarization of HCs. Double transgenic fish carrying SynaptopHluorin in cones and FaNaC in horizontal cells were generated by crossing SynaptopHluorin and FaNaC fish lines. FMRFamide $(30 \mu \mathrm{M})$ added at time 0 caused a decrease in SynaptopHluorin fluorescence in retinas from the double-transgenic fish $\left({ }^{* * *} p=0.0005\right)$ but not in the retina from the SynaptopHluorin single-transgenic fish. Preincubation with GYKI and Nifedipine did not have an effect on the FMRFamide-elicited acidification, i.e., calcium channels on the $\mathrm{HC}$ side are not responsible for this effect.

A

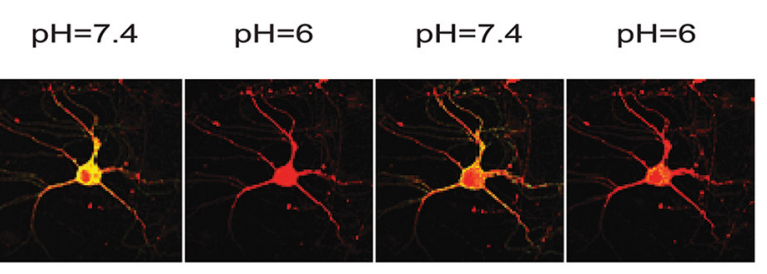

B Hippocampal Cell Soma Hippocampal Cell Dendrites

C

$\stackrel{0.2}{F / F_{0} L}$<smiles>CCCCCCCCCCCCCCCCCCCCC</smiles>
$50 \mathrm{~s}$

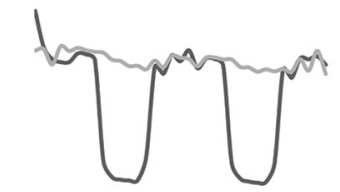

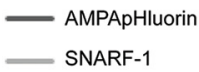

D

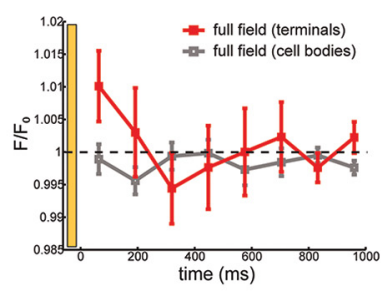

E

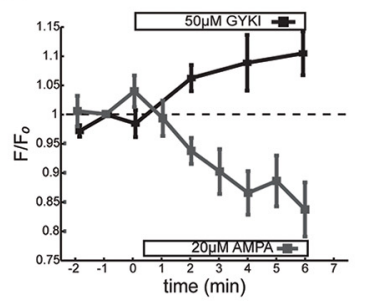

$\mathbf{F}$



G

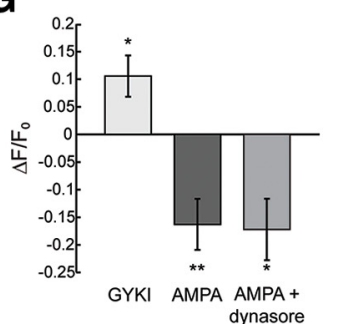

Figure 6. AMPApHluorin expressed in $\mathrm{HC}$ dendrites reports changes in $\mathrm{pH}$ in the synaptic cleft. $\boldsymbol{A}$, During the first scan after a light flash (yellow bar), AMPApHluorin fluorescence $(\boldsymbol{F})$ was increased by $1 \%$ compared with the preflash level $\left(F_{0}\right)$. No fluorescence change was reported by AMPApHluorin in HC somata. $\boldsymbol{B}$, AMPApHluorin fluorescence in isolated retinae was monitored after treatment with either GYKI or AMPA. GYKI induced an increase in AMPApHluorin fluorescence indicating trafficking of GluR2 to the HC terminal surface. In contrast, AMPA treatment led to an internalization of GluR2 as demonstrated by the decrease of AMPApHluorin fluorescence on the HC terminal surface. Together, this shows that AMPApHluorin can serve as a receptor for GluR2 trafficking and that HCs exhibit some form of plasticity. ${ }^{*} p<0.05,{ }^{* *} p<0.01$. C, Application of dynasore $(80 \mu \mathrm{m})$ had no effect on the decrease in fluorescence noted after the application of AMPA. D, Bar graph presentation of the results in $\boldsymbol{B}$ and $\boldsymbol{C}$. $\boldsymbol{E}$, Fluorescence images of a dissociated cultured hippocampal neuron, transfected with CMV-AMPApHluorin superfused with buffer solutions at varying pH. $\boldsymbol{F}$, The fluorescence intensity of cell soma and dendrites (G) dropped upon applying acidic the extracellular buffer solution from pH 7.4 to 6 and recovered after returning to pH 7.4. $\boldsymbol{H}$, AMPApHluorin fluorescence was reversible and quenched to the background level after superfusing the retina with $\mathrm{pH} 5.5$ solution. Accessibility to buffer is consistent with the signal arising from probes on the cell-surface. Data are plotted as mean \pm SEM.

with different $\mathrm{pH}$ values. Fluorescence dropped rapidly (within seconds) in both hippocampal cell somas (Fig. 6A) and dendrites (Fig. $6 B$ ) upon acidification of extracellular $\mathrm{pH}$ from 7.4 to 6 , and was fully restored when $\mathrm{pH}$ was raised to 7.4 (Fig. $6 \mathrm{C}$ ), consistent with pHluorin displayed on the cell surface (Sankaranarayanan and Ryan, 2000). In contrast, no signal was detected in
AMPApHluorin-free neurons that had been preloaded with 20 $\mu \mathrm{M}$ seminaphtharhodafluor (SNARF), an intracellular fluorescent $\mathrm{pH}$ indicator (Figs. $6 \mathrm{~A}-\mathrm{C}$ ). As a further test for cell-surface origin of the fluorescence signal, we modified AMPApHluorin by inserting a thrombin proteolytic cleavage site between the extracellular pHluorin region and the AMPA receptor. Throm- 
bin $(10 \mathrm{U} / \mathrm{ml})$ treatment of cells expressing this construct resulted in elimination of cell-surface fluorescence, verifying that AMPApHluorin on the cell surface. Next, we expressed AMPAphluorin in transgenic zebrafish retina and measured fluorescence at different $\mathrm{pH}$ conditions. We showed that AMPAphluorin fluorescence was reversible and quenched to the background level after superfusing the retina with $\mathrm{pH} 5.5$ solution (Fig. 6D).

We next asked whether AMPApHluorin, expressed in the transgenic zebrafish retina on HCs, can detect a change in $\mathrm{pH}$ mediated by synaptic feedback (Fig. $6 E$ ). Following a light flash, we observed a small but significant, increase in fluorescence (1\%) during the first scan after light offset $\left(F / F_{0}=1.010 \pm 0.005, n=\right.$ $17, p=0.0025)$ decaying to baseline in later scans. The initial increase was detected in terminals, but not in HC somata $(F /$ $F_{0}=0.998 \pm 0.002 n=23, p=0.63$; Fig. $6 E$ ). These results suggest that AMPApHluorin on the HCs does detect synaptic alkalinization. However, because on the probe is located, on the average, further from its source (Fig. $3 C, D$ ), the signal is smaller than that detected by CalipHluorin $\left(p=2.2 \times 10^{-5}\right)$. The $1 \%$ difference in fluorescence detected by AMPApHluorin was not statistically different from the $2 \%$ change detected by SynaptopHluorin $(p=0.07)$.

To further verify that the fluorescence change in retina originates from AMPApHluorin on the HC cell surface and not intracellular compartments, we measured the effect of changing extracellular $\mathrm{pH}$, achieved by washing with saline containing MES (20 mM), a membrane-impermeant $\mathrm{pH}$ buffer. The initial normalized fluorescence $\left(F / F_{0}=1 \pm 0.09, n=20\right)$ dropped after changing the extracellular $\mathrm{pH}$ from 7.4 to $5.5\left(F / F_{0}=0.1 \pm 0.03\right.$, $\left.n=20, p=2.3 \times 10^{-10}\right)$, reversing upon return to $\mathrm{pH}$ $7.4\left(F / F_{0}=1.02 \pm 0.11, p=0.8\right)$. The accessibility of AMPApHluorin to extracellular $\mathrm{pH}$ change is once again consistent with cell-surface origin of the signal.

In addition to responding to light-induced HC feedback, AMPApHluorin also responded to application of an agonist or competitive antagonist of the ionotropic glutamate receptors on HCs. Addition of AMPA $(20 \mu \mathrm{M})$, led to a decrease in AMPApHluorin fluorescence of $17 \%\left(F / F_{0}=0.837 \pm 0.04, n=\right.$ $14, p=0.0037$; Fig. $6 F$ ), consistent with depolarization of HCs causing acidification of the extracellular $\mathrm{pH}$. By contrast, an antagonist of the receptors, GYKI $(50 \mu \mathrm{M})$, led to an increase of in fluorescence of $11 \%$ $(1.105 \pm 0.037, n=8, p=0.013$; Fig. $6 F)$, consistent with hyperpolarization of HCs alkalinizing extracellular $\mathrm{pH}$.

As explained earlier, the magnitude of AMPApHluorin fluorescence depends on two factors: the expression density of the probe on the cell surface, and the value of the extracellular $\mathrm{pH}$. We considered the possibility that $\mathrm{HC}$ voltage changes might lead to a change in the cell-surface density of AMPApHluorin. AMPA receptors are inserted into the plasma membrane by exocytosis and removed by endocytosis, but activity-dependent alteration of both processes requires many minutes, both in neurons in the brain (Wang and Linden, 2000; Passafaro et al., 2001) and the retina (Xia et al., 2006; Casimiro et al., 2013). In contrast, the light-elicited AMPApHluorin signal occurs within $1 \mathrm{~s}$ (Fig. 6E). Moreover, AMPA receptor endocytosis is dependent on clathrin and dynamin and it is blocked by the dynamin inhibitor dynasore (Macia et al., 2006). We found that the agonist-induced decrease in AMPApHluorin signal is unaffected by $80 \mu \mathrm{M}$ dynasore $(0.83 \pm 0.11, n=10, p=0.02$; Fig. $6 F, G))$. Together, these results suggest that changes in the AMPApHluorin signal reflects a change in the extracellular $\mathrm{pH}$, and not a change in the number of probes on the surface of a cell.

\section{$\mathrm{pH}$ changes are locally constrained}

Synaptically released glutamate can spill-over not only between individual ribbon-associated active zones within a cone terminal, but between different cone terminals, resulting in cross talk (Szmajda and Devries, 2011). This raises the question of whether protons spill over between invaginations within an individual terminal and whether they spill over between different terminals. We measured the minimal path length a proton would need to travel to get from the base of one ribbon, where HC feedback appears to be focused, to a neighboring ribbon. We analyzed electron micrograph sections that included at least two ribbons, each terminating at the presynaptic membrane (Fig. 7A). The average minimal extracellular distance measured between ribbon bases was $4908 \pm 655 \mathrm{~nm}$; range $567-$ $13,316 \mathrm{~nm} n=56$ (Fig. $7 B$ ).

How does the profile of $\mathrm{pH}$ measured by the three pHluorin probes compare with the inter-ribbon distance? The voltagegated $\mathrm{Ca}^{2+}$ channels that control neurotransmitter release are situated 200-300 nm from ribbons (Raviola and Gilula, 1975). Consequently, the CalipHluorin, which is derived from a subunit of the channel, is also located at this site, as confirmed by our immunolabeling results (Fig. 2). After a flash of light, the fluorescence change reported by CalipHluorin (Wang et al., 2014), SynaptopHluorin (Fig. 4A) and AMPApHluorin (Fig. 6A) are 5, 2, and $1 \%$, respectively (Fig. $7 C$ ), correlated with their average distance from the ribbon (Fig. 3D).

Taking this into account, an exponential fit of the $\mathrm{pH}$ profile predicts no significant signal at the average inter-ribbon distance of $\sim 4.9 \mu \mathrm{m}$, almost $90 \%$ decline of the signal at the minimum measured inter-ribbon distance of $\sim 1 \mu \mathrm{m}$, exhibited by $<5 \%$ of observed ribbon pairs. Even more attenuated is signal spread to neighboring cone terminals. The specific profile of the $\mathrm{pH}$ signal depends on the uniformity of the extracellular $\mathrm{pH}$ buffers and the proton transporters along the cleft, but our results make significant proton spillover very unlikely.

\section{Discussion}

\section{pHluorin as a tool for mapping $\mathrm{pH}$ gradients}

A variety of tools have been used to measure extracellular $\mathrm{pH}$ and elucidate the role of protons as a putative neurotransmitter in the nervous system. For many decades, $\mathrm{pH}$-specific microelectrodes have been available for measuring $\mathrm{pH}$ in the extracellular space (Chesler, 1990). However, these electrodes were invasive and difficult to manufacture, and suffered from high noise, greatly limiting spatial and temporal resolution. To lower noise, a selfreferencing $\mathrm{pH}$ electrode was devised by repeatedly vibrating the probe between two extracellular positions (Kreitzer et al., 2007). Although this system is accurate and fast, it cannot be used in the intact retina without disrupting the complex architecture of synaptic connections.

Fluorescent biosensors for $\mathrm{pH}$, such as SNARF, can be used for noninvasive optical detection of $\mathrm{pH}$ changes (Buckler and Vaughan-Jones, 1990). However, rapid diffusion of this small molecule precludes spatial resolution of $\mathrm{pH}$ gradient at the scale of a cone terminal. Finally, genetically-encoded $\mathrm{pH}$ sensors based on pHluorin can be expressed in a cell-type-specific fashion to sense $\mathrm{pH}$ changes at an individual synapse (Miesenböck et al., 1998). pHluorin can be spliced onto a wide variety of protein platforms, to detect the fusion of synaptic vesicles with the plasma membrane, or to follow protein trafficking to or from the cell surface (Rajappa et al., 2016). Here we are using pHluorin to report on rapid changes in $\mathrm{pH}$, entirely in the extracellular space. By attaching pHluorin to protein platforms that are displayed on 
A
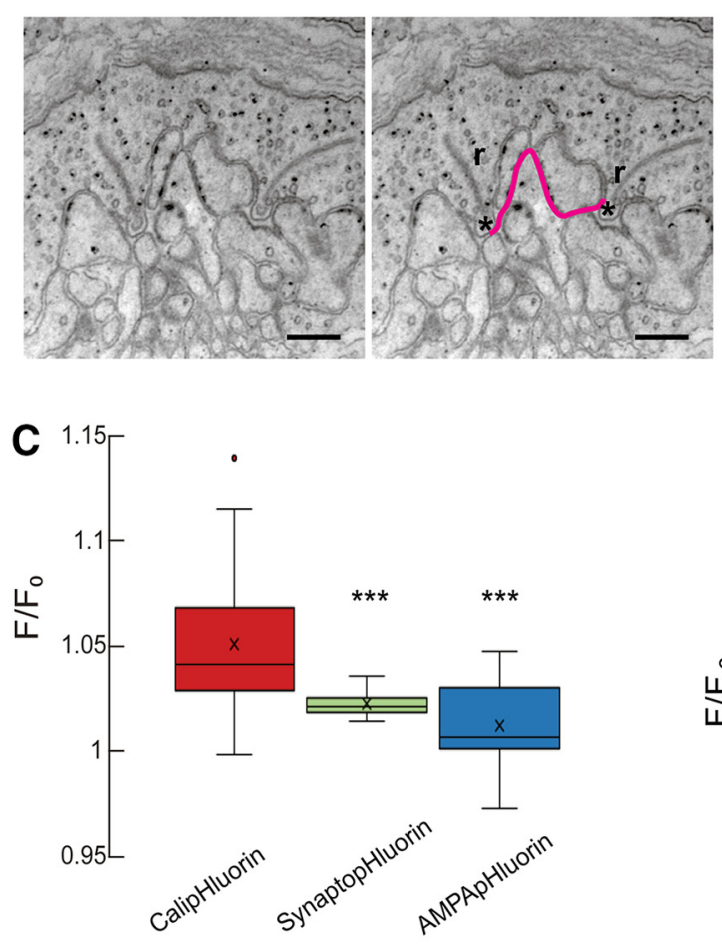

B

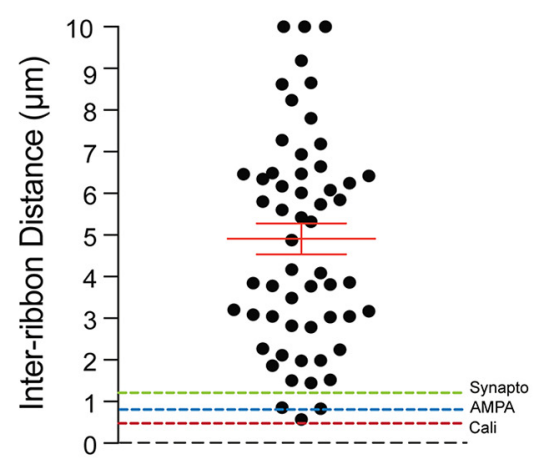

D

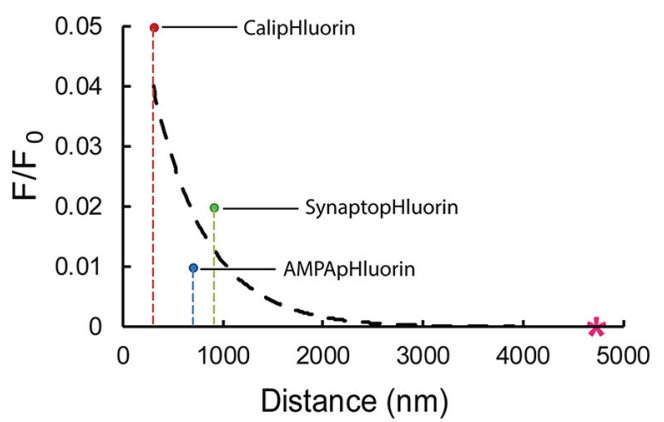

Figure 7. pH changes drop rapidly with distance and are likely constrained to each invagination. $A$, Electron micrographs from synaptic invaginations of zebrafish. The shortest extracellular path was measured between the bases of adjacent ribbons, where they abut the plasma membrane $(n=56)$. Ribbons are marked with $r$, arcuate density at the ribbon base is marked with an asterisk $\left(^{*}\right)$. Scale bar, $500 \mathrm{~nm}$. B, Distribution of inter-ribbon distances, with a mean value of $4908 \pm 655 \mathrm{~nm}$. C, Summary of the average change in fluorescence after a light flash reported by each of the three $\mathrm{pH}$ probes. CalipHluorin results were adapted with permission from Wang et al., 2014. Analysis was performed with one-way ANOVA, $F_{(2.53)}=13.21, p=2.2 \times 10^{-5}$. $D$, The change in fluorescence with distance from the ribbon was fitted to the exponential curve using the equation $y=0.0702 \mathrm{e}^{-0.002 x}\left(R^{2}=0.4989\right)$ based on the locations of peak radial intensity for each probe (Fig. 3D), with CalipHluorin at $300 \mathrm{~nm}$ from the ribbon. The predicted change in fluorescence at the average inter-ribbon distance is marked with an asterisk.

the cell surface but differ in their precise location, we have mapped the $\mathrm{pH}$ profile in the synaptic cleft and identified the region very near the synaptic ribbon as the crucial spot with the largest $\mathrm{HC}$ feedback-elicited $\mathrm{pH}$ change.

\section{The proton hypothesis of negative feedback in the outer retina}

According to the $\mathrm{pH}$ hypothesis of negative feedback, the hyperpolarization of the $\mathrm{HC}$ membrane potential during the light response drives influx of protons through a channel or transporter in $\mathrm{HC}$ dendrites, leading to alkalinization of the synaptic cleft (reviewed by Kramer and Davenport, 2015). Alternative scenarios have also been proposed that could more indirectly change extracellular $\mathrm{pH}$ in response to a voltage change in HCs. These include transport of the $\mathrm{pH}$ buffer bicarbonate across the HC membrane (Warren et al., 2016b), or flux of ATP through pannexin channels, which through ecto-ATPase-elicited hydrolysis, may lead to liberation of protons in the synaptic cleft (Vroman et al., 2014). Although there is debate about the relative importance of these mechanisms for changing extracellular proton concentration, there is a growing consensus that the change in extracellular $\mathrm{pH}$ is the crucial event that alters the gating of L-type $\mathrm{Ca}^{2+}$ channels in cones, changing the rate of $\mathrm{Ca}^{2+}$-dependent exocytosis of glutamate-filled synaptic vesicles at the synaptic ribbon (Thoreson and Mangel, 2012; Kramer and Davenport, 2015). It should be noted that fusion of these vesicles also contributes protons to the extracellular space, which itself inhibits L-type $\mathrm{Ca}^{+2}$ channels (DeVries, 2001); however, this process is too transient to be detected by CalipHluorin (Wang et al., 2014).
Various lines of evidence support the hypothesis that a $\mathrm{pH}$ change is the critical signal responsible for negative feedback. Artificially acidifying or alkalinizing the synaptic cleft modulates the voltage-dependent gating of cone $\mathrm{Ca}^{2+}$ channels, enough to account for HC feedback (Davenport et al., 2008; Fahrenfort et al., 2009). Adding a strong $\mathrm{pH}$ buffer, such as HEPES, suppresses HC feedback (Hirasawa and Kaneko, 2003; Trenholm and Baldridge, 2010) and eliminates the antagonistic receptive field surround of neurons further along in the visual system (Davenport et al., 2008). Finally, the development of CalipHluorin as a genetically-encoded $\mathrm{pH}$ probe has enabled direct demonstration of synaptic cleft alkalinization in response to $\mathrm{HC}$ hyperpolarization (Wang et al., 2014). Our current results with SynaptopHluorin and AMPApHluorin add new evidence further supporting the $\mathrm{pH}$ hypothesis.

\section{Spatial spread and constraint of synaptic signals in the outer retina}

The ribbon synapse lies in the deepest recess of an invagination formed within the cone terminal. Muller glial cells wrap around the terminal and possess glutamate transporters that actively remove glutamate from the extracellular space (Burris et al., 2002; Sarthy et al., 2005). Despite these impediments, results from paired cone-cone patch-clamp recordings show that glutamate can spill over, operating in milliseconds to spread light-elicited signals between neighboring terminals in the cone network (Szmajda and Devries, 2011). In contrast, our results suggest that the $\mathrm{HC}$ feedback-induced $\mathrm{pH}$ change at one cone terminal does not substantially spill over to neighboring cones. Even though 
our three probes all contain the identical pH sensor (i.e., pHluorin), they are displayed in different locations in the synaptic cleft and consequently, they exhibited different magnitude changes in fluorescence after a full-field light stimulus. CalipHluorin, tightly localized near the ribbon, registered a $5 \%$ increase in fluorescence after light (Figure 2C; Wang et al., 2014). SynaptopHluorin, more broadly displayed throughout cone terminals, registered a $2 \%$ increase in fluorescence (Fig. 4A). AMPApHluorin, on the HC dendrites and somata, registered a $1 \%$ increase (Fig. $6 A$ ). All three probes were overexpressed in the zebrafish retina, so probe locations do not exactly reflect the normal distribution of the parent protein in wild-type fish. Nonetheless, probe locations seen with two-photon imaging are consistent with the patterns of the native parent proteins described previously (Morgans et al., 1996; Morgans, 2001; Klooster et al., 2009; De Sevilla Müller et al., 2013). These include rosettes of CalipHluorin and AMPApHluorin that correspond to ultrastructural observation of clusters of $\mathrm{Ca}^{2+}$ channel proteins (Lv et al., 2012) and AMPA receptor subunits (Klooster et al., 2009), respectively. By appearing at different geographic locations, the probes allow quantitative comparison of the $\mathrm{pH}$ change at different positions relative to the synaptic ribbon, a common geographic landmark.

Our observations suggest that the feedback mechanism that controls synaptic $\mathrm{pH}$ appears to be focused at the site where it can have the largest effect on cone neurotransmitter release. Moreover, the sharp decline in the HC feedback-elicited change in fluorescence with probes located further from the ribbon suggests little or no spillover of $\mathrm{pH}$ transients from illuminated cones to non-illuminated neighbors, at least following brief (milliseconds to seconds) light flashes. It is possible that $\mathrm{pH}$ fluctuates in a more coordinated manner during longer-term light or dark adaptation (Dmitriev and Mangel, 2004), but our results suggest that there is little cross talk between cone terminals during dynamic changes in visual scenes.

The lack of cross talk is consistent with strong $\mathrm{pH}$ buffers and transporters removing protons from the extracellular space, as well as the tortuous and narrow path that protons must travel to affect neighboring terminals. Glutamate spillover requires only that the neurotransmitter reach glutamate receptors or transporters, which are widely distributed all over a neighboring terminal (Haverkamp et al., 2000). In contrast, $\mathrm{pH}$ spillover would require diffusion of protons all the way out of one invagination and all the way up to the apex of another invagination where the $\mathrm{L}$-type $\mathrm{Ca}^{2+}$ channels are tightly localized.

Synaptic contacts in cone terminals in zebrafish appear as rosettes (Song et al., 2008), which manifest as a ring of labeled CalipHluorin and AMPApHluorin puncta in our studies. It is interesting that these puncta are evenly spaced and lie near the perimeter of the terminal, suggesting maximization of the distance between nearest neighbors. Cone invaginating synapses typically possess a single bipolar cell dendrite flanked by two lateral HC dendrites. Compartmentalizing $\mathrm{pH}$ signals ensures that each invaginating synapse computes feedback independently from neighboring invaginating synapses, complementing independent operation of ribbon-mediated synaptic vesicle release (Grassmeyer and Thoreson, 2017). By maintaining independence of feedback signaling, each invagination could make a unique calculation, collecting and comparing inputs from the two HCs, each with a unique receptive field, and outputting this information to different types of bipolar cells. At the same time, spillover of glutamate between invaginations, and further between terminals, can maximize sensitivity of feedforward signaling.

In addition to negative feedback on cones triggered by HC membrane hyperpolarization, HCs also exert positive feedback, triggered by a change in intracellular $\mathrm{Ca}^{2+}$ in $\mathrm{HCs}$ (Jackman et al., 2011). Activation of $\mathrm{Ca}^{2+}$-permeant AMPA receptors in $\mathrm{HC}$ dendrites triggers $\mathrm{Ca}^{2+}$-dependent release of an unidentified neurotransmitter that enhances cone neurotransmitter release. Interestingly, the spatial spread of the intracellular triggers for negative and positive feedback from HCs differ. Negative feedback by HCs is distributed over a large area because membrane hyperpolarization spreads electrotonically though the low cytoplasmic resistance of an individual HC, and through gap junctions that couple many HCs. In contrast, positive feedback from HCs is spatially limited to individual cone terminals because the spread of intracellular $\mathrm{Ca}^{2+}$ is constrained to an individual HC dendrite by cytoplasmic $\mathrm{Ca}^{2+}$ buffers. The interplay between spatial spread versus spatial constraint of both intracellular and extracellular signals is a recurring theme in the outer retina, functioning to adjust both visual sensitivity and visual acuity over a wide range of illumination conditions.

\section{References}

Ashby MC, De La Rue SA, Ralph GS, Uney J, Collingridge GL, Henley JM (2004) Removal of AMPA receptors (AMPARs) from synapses is preceded by transient endocytosis of extrasynaptic AMPARs. J Neurosci 24: 5172-5176. CrossRef Medline

Buckler KJ, Vaughan-Jones RD (1990) Application of a new pH-sensitive fluoroprobe (carboxy-SNARF-1) for intracellular $\mathrm{pH}$ measurement in small, isolated cells. Pflugers Arch 417:234-239. CrossRef Medline

Burris C, Klug K, Ngo IT, Sterling P, Schein S (2002) How muller glial cells in macaque fovea coat and isolate the synaptic terminals of cone photoreceptors. J Comp Neurol 453:100-111. CrossRef Medline

Byzov AL, Shura-Bura TM (1986) Electrical feedback mechanism in the processing of signals in the outer plexiform layer of the retina. Vision Res 26:33-44. CrossRef Medline

Cadetti L, Thoreson WB (2006) Feedback effects of horizontal cell membrane potential on cone calcium currents studied with simultaneous recordings. J Neurophysiol 95:1992-1995. CrossRef Medline

Campbell FW, Robson JG (1968) Application of fourier analysis to the visibility of gratings. J Physiol 197:551-566. CrossRef Medline

Casimiro TM, Nawy S, Carroll RC (2013) Molecular mechanisms underlying activity-dependent AMPA receptor cycling in retinal ganglion cells. Mol Cell Neurosci 56:384-392. CrossRef Medline

Cenedese V, de Graaff W, Csikós T, Poovayya M, Zoidl G, Kamermans M (2017) Pannexin 1 is critically involved in feedback from horizontal cells to cones. Front Mol Neurosci 10:403. CrossRef Medline

Chapot CA, Behrens C, Rogerson LE, Baden T, Pop S, Berens P, Euler T, Schubert T (2017) Local signals in mouse horizontal cell dendrites. Curr Biol 27:3603-3615.e5. CrossRef Medline

Chesler M (1990) The regulation and modulation of $\mathrm{pH}$ in the nervous system. Prog Neurobiol 34:401-427. CrossRef Medline

Daniels BA, Baldridge WH (2011) The light-induced reduction of horizontal cell receptive field size in the goldfish retina involves nitric oxide. Vis Neurosci 28:137-144. CrossRef Medline

Davenport CM, Detwiler PB, Dacey DM (2008) Effects of pH buffering on horizontal and ganglion cell light responses in primate retina: evidence for the proton hypothesis of surround formation. J Neurosci 28:456-464. CrossRef Medline

De Sevilla Müller LP, Liu J, Solomon A, Rodriguez A, Brecha NC (2013) Expression of voltage-gated calcium channel $\alpha_{2} \delta_{4}$ subunits in the mouse and rat retina. J Comp Neurol 521:2486-2501. CrossRef Medline

Denk W, Detwiler PB (1999) Optical recording of light-evoked calcium signals in the functionally intact retina. Proc Natl Acad Sci U S A 96:70357040. CrossRef Medline

DeVries SH (2001) Exocytosed protons feedback to suppress the $\mathrm{Ca}^{2+}$ current in mammalian cone photoreceptors. Neuron 32:1107-1117. CrossRef Medline

Dmitriev AV, Mangel SC (2004) Retinal pH reflects retinal energy metabolism in the day and night. J Neurophysiol 91:2404-2412. CrossRef Medline

Fahrenfort I, Steijaert M, Sjoerdsma T, Vickers E, Ripps H, van Asselt J, Endeman D, Klooster J, Numan R, ten Eikelder H, von Gersdorff H, Kamermans M (2009) Hemichannel-mediated and pH-based feedback 
from horizontal cells to cones in the vertebrate retina. PLoS One 4:e6090. CrossRef Medline

Grassmeyer JJ, Thoreson WB (2017) Synaptic ribbon active zones in cone photoreceptors operate independently from one another. Front Cell Neurosci 11:198. CrossRef Medline

Haverkamp S, Grünert U, Wässle H (2000) The cone pedicle, a complex synapse in the retina. Neuron 27:85-95. CrossRef Medline

Haverkamp S, Grünert U, Wässle H (2001) The synaptic architecture of AMPA receptors at the cone pedicle of the primate retina. J Neurosci 21:2488-2500. CrossRef Medline

Hirasawa H, Kaneko A (2003) pH changes in the invaginating synaptic cleft mediate feedback from horizontal cells to cone photoreceptors by modulating $\mathrm{Ca}^{2+}$ channels. J Gen Physiol 122:657-671. CrossRef Medline

Holzhausen LC, Lewis AA, Cheong KK, Brockerhoff SE (2009) Differential role for synaptojanin 1 in rod and cone photoreceptors. J Comp Neurol 517:633-644. CrossRef Medline

Jackman SL, Babai N, Chambers JJ, Thoreson WB, Kramer RH (2011) A positive feedback synapse from retinal horizontal cells to cone photoreceptors. PLoS Biol 9:e1001057. CrossRef Medline

Kamermans M, Fahrenfort I, Schultz K, Janssen-Bienhold U, Sjoerdsma T, Weiler R (2001) Hemichannel-mediated inhibition in the outer retina. Science 292:1178-1180. CrossRef Medline

Kennedy BN, Alvarez Y, Brockerhoff SE, Stearns GW, Sapetto-Rebow B, Taylor MR, Hurley JB (2007) Identification of a zebrafish cone photoreceptor-specific promoter and genetic rescue of achromatopsia in the nof mutant. Invest Ophthalmol Vis Sci 48:522-529. CrossRef Medline

Klooster J, Yazulla S, Kamermans M (2009) Ultrastructural analysis of the glutamatergic system in the outer plexiform layer of zebrafish retina. J Chem Neuroanat 37:254-265. CrossRef Medline

Kramer RH, Davenport CM (2015) Lateral inhibition in the vertebrate retina: the case of the missing neurotransmitter. PLoS Biol 13:e1002322. CrossRef Medline

Kreitzer MA, Collis LP, Molina AJ, Smith PJ, Malchow RP (2007) Modulation of extracellular proton fluxes from retinal horizontal cells of the catfish by depolarization and glutamate. J Gen Physiol 130:169-182. CrossRef Medline

Kwan KM, Fujimoto E, Grabher C, Mangum BD, Hardy ME, Campbell DS, Parant JM, Yost HJ, Kanki JP, Chien CB (2007) The Tol2kit: a multisite gateway-based construction kit for Tol2 transposon transgenesis constructs. Dev Dyn 236:3088-3099. CrossRef Medline

Lingueglia E, Champigny G, Lazdunski M, Barbry P (1995) Cloning of the amiloride-sensitive FMRFamide peptide-gated sodium channel. Nature 378:730-733. CrossRef Medline

Lv P, Sihn CR, Wang W, Shen H, Kim HJ, Rocha-Sanchez SM, Yamoah EN (2012) Posthearing $\mathrm{Ca}^{2+}$ currents and their roles in shaping the different modes of firing of spiral ganglion neurons. J Neurosci 32:16314-16330. CrossRef Medline

Macia E, Ehrlich M, Massol R, Boucrot E, Brunner C, Kirchhausen T (2006) Dynasore: a cell-permeable inhibitor of dynamin. Dev Cell 10:839-850. CrossRef Medline

Mercer AJ, Chen M, Thoreson WB (2011) Lateral mobility of presynaptic L-type calcium channels at photoreceptor ribbon synapses. J Neurosci 31:4397-4406. CrossRef Medline

Miesenböck G, De Angelis DA, Rothman JE (1998) Visualizing secretion and synaptic transmission with $\mathrm{pH}$-sensitive green fluorescent proteins. Nature 394:192-195. CrossRef Medline

Morgans CW (2001) Localization of the $\alpha_{1 \mathrm{~F}}$ calcium channel subunit in the rat retina. Invest Ophthalmol Vis Sci 42:2414-2418. Medline

Morgans CW, Brandstätter JH, Kellerman J, Betz H, Wässle H (1996) A SNARE complex containing syntaxin 3 is present in ribbon synapses of the retina. J Neurosci 16:6713-6721. CrossRef Medline

Passafaro M, Piëch V, Sheng M (2001) Subunit-specific temporal and spatial patterns of AMPA receptor exocytosis in hippocampal neurons. Nat Neurosci 4:917-926. CrossRef Medline

Pologruto TA, Sabatini BL, Svoboda K (2003) ScanImage: flexible software for operating laser scanning microscopes. Biomed Eng Online 2:13. CrossRef Medline

Rajappa R, Gauthier-Kemper A, Böning D, Hüve J, Klingauf J (2016) Synaptophysin 1 clears synaptobrevin 2 from the presynaptic active zone to prevent short-term depression. Cell Rep 14:1369-1381. CrossRef Medline
Raviola E, Gilula NB (1975) Intramembrane organization of specialized contacts in the outer plexiform layer of the retina: a freeze-fracture study in monkeys and rabbits. J Cell Biol 65:192-222. CrossRef Medline

Rea R, Li J, Dharia A, Levitan ES, Sterling P, Kramer RH (2004) Streamlined synaptic vesicle cycle in cone photoreceptor terminals. Neuron 41:755766. CrossRef Medline

Sankaranarayanan S, Ryan TA (2000) Real-time measurements of vesicleSNARE recycling in synapses of the central nervous system. Nat Cell Biol 2:197-204. CrossRef Medline

Sarthy VP, Pignataro L, Pannicke T, Weick M, Reichenbach A, Harada T, Tanaka K, Marc R (2005) Glutamate transport by retinal Muller cells in glutamate/aspartate transporter-knockout mice. Glia 49:184-196. CrossRef Medline

Schmitz F, Königstorfer A, Südhof TC (2000) RIBEYE, a component of synaptic ribbons: a protein's journey through evolution provides insight into synaptic ribbon function. Neuron 28:857-872. CrossRef Medline

Schwartz EA (1982) Calcium-independent release of GABA from isolated horizontal cells of the toad retina. J Physiol 323:211-227. CrossRef Medline

Shields CR, Klooster J, Claassen Y, Ul-Hussain M, Zoidl G, Dermietzel R, Kamermans M (2007) Retinal horizontal cell-specific promoter activity and protein expression of zebrafish connexin 52.6 and connexin 55.5. J Comp Neurol 501:765-779. CrossRef Medline

Song PI, Matsui JI, Dowling JE (2008) Morphological types and connectivity of horizontal cells found in the adult zebrafish (Danio rerio) retina. J Comp Neurol 506:328-338. CrossRef Medline

Svoboda K, Yasuda R (2006) Principles of two-photon excitation microscopy and its applications to neuroscience. Neuron 50:823-839. CrossRef Medline

Szmajda BA, Devries SH (2011) Glutamate spillover between mammalian cone photoreceptors. J Neurosci 31:13431-13441. CrossRef Medline

Thoreson WB, Burkhardt DA (1990) Effects of synaptic blocking agents on the depolarizing responses of turtle cones evoked by surround illumination. Vis Neurosci 5:571-583. CrossRef Medline

Thoreson WB, Mangel SC (2012) Lateral interactions in the outer retina. Prog Retin Eye Res 31:407-441. CrossRef Medline

Tomita T (1965) Electrophysiological study of the mechanisms subserving color coding in the fish retina. Cold Spring Harb Symp Quant Biol 30: 559-566. CrossRef Medline

Trenholm S, Baldridge WH (2010) The effect of aminosulfonate buffers on the light responses and intracellular $\mathrm{pH}$ of goldfish retinal horizontal cells. J Neurochem 115:102-111. CrossRef Medline

Verweij J, Kamermans M, Spekreijse H (1996) Horizontal cells feed back to cones by shifting the cone calcium-current activation range. Vision Res 36:3943-3953. CrossRef Medline

Vessey JP, Stratis AK, Daniels BA, Da Silva N, Jonz MG, Lalonde MR, Baldridge WH, Barnes S (2005) Proton-mediated feedback inhibition of presynaptic calcium channels at the cone photoreceptor synapse. J Neurosci 25:4108-4117. CrossRef Medline

Vroman R, Klaassen LJ, Howlett MH, Cenedese V, Klooster J, Sjoerdsma T, Kamermans M (2014) Extracellular ATP hydrolysis inhibits synaptic transmission by increasing $\mathrm{pH}$ buffering in the synaptic cleft. PLoS Biol 12:e1001864. CrossRef Medline

Wang TM, Holzhausen LC, Kramer RH (2014) Imaging an optogenetic pH sensor reveals that protons mediate lateral inhibition in the retina. Nat Neurosci 17:262-268. CrossRef Medline

Wang YT, Linden DJ (2000) Expression of cerebellar long-term depression requires postsynaptic clathrin-mediated endocytosis. Neuron 25:635647. CrossRef Medline

Warren TJ, Van Hook MJ, Tranchina D, Thoreson WB (2016a) Kinetics of inhibitory feedback from horizontal cells to photoreceptors: implications for an ephaptic mechanism. J Neurosci 36:10075-10088. CrossRef Medline

Warren TJ, Van Hook MJ, Supuran CT, Thoreson WB (2016b) Sources of protons and a role for bicarbonate in inhibitory feedback from horizontal cells to cones in Ambystoma tigrinum retina. J Physiol 594:6661-6677. CrossRef Medline

Wu SM (1991) Input-output relations of the feedback synapse between horizontal cells and cones in the tiger salamander retina. J Neurophysiol 65:1197-1206. CrossRef Medline

Xia Y, Carroll RC, Nawy S (2006) State-dependent AMPA receptor trafficking in the mammalian retina. J Neurosci 26:5028-5036. CrossRef Medline 